Freire, M. C. \& Leal, Susana (2016). O efeito moderador do significado do trabalho na relação entre a liderança ética e a satisfação dos colaboradores. VI Conferência em Investigação e Intervenção em RH. 18 e 19 de fevereiro de 2016. Escola Superior de Ciências Empresariais (ESCE) do Instituto Politécnico de Setúbal (IPS). http://www.eseig.ipp.pt/conferencias/index.php/iirh/viconferencia-ii (Abstract)

\title{
O EFEITO MODERADOR DO SIGNIFICADO DO TRABALHO NA RELAÇÃO ENTRE A LIDERANÇA ÉTICA E A SATISFAÇÃO DOS COLABORADORES
}

\author{
Maria do Céu Freire \\ Associação dos Lares dos Ferroviários \\ Mestranda em Gestão de Organizações de Economia Social - Escola Superior de Gestão e \\ Tecnologia de Santarém \\ ceufreire12@gmail.com
}

\begin{abstract}
Susana Leal
Instituto Politécnico de Santarém e Centro de Investigação em Qualidade de Vida

susana.leal@esg.ipsantarem.pt
\end{abstract}

\section{Resumo}

Objetivo. Esta pesquisa testa empiricamente a relação entre se o significado do trabalho modera a relação entre as perceções de liderança ética e a satisfação no trabalho. A relação entre liderança e satisfação dos colaboradores tem sido estudada por muitos investigadores em diversos contextos, sobretudo na área da saúde, do ensino e em organizações com fins lucrativos, sendo escassos os estudos aplicados no sector social. Embora seja profícua a investigação que considera a liderança e a satisfação, é menos frequente aquela que: (a) considera a liderança ética, (b) considera as perceções de colaboradores do sector social.

Metodologia. A amostra abarca 97 colaboradores ( $90 \%$ do género feminino, $45 \%$ com o 9. ano de escolaridade, $28 \%$ com o secundário e $27 \%$ com um curso superior, $14 \%$ desempenham funções de chefia) provenientes de três Instituições Particulares de Solidariedade Social. A idade média dos inquiridos cifra-se nos 43,8 anos (DP: 11,1) e a antiguidade média em 11,1 anos (DP: 7,7). A liderança ética foi estudada com a escala de De Hoogh e Den Hartog, (2008), abarcando três dimensões: moralidade e justiça, clarificação do papel dos colaboradores, e partilha de poder. A satisfação foi medida através da escala de Fields (2002). O significado no trabalho foi medido através dos itens propostos por Rego e Cunha (2013). Controlou-se o efeito do género, da idade, das habilitações académicas, da antiguidade na organização, da antiguidade na relação com o líder, do tipo de vínculo e do exercício de funções de chefia.

Resultados. Os dados sugerem o seguinte: (a) as perceções de liderança ética influenciam de modo positivo e significativo os níveis de satisfação das pessoas no trabalho; (b) a relação entre a liderança ética e a satisfação é moderada pelo significado no trabalho. Os trabalhadores que sentem que realizam um trabalho com significado para a sua vida e útil para as pessoas e a 
Freire, M. C. \& Leal, Susana (2016). O efeito moderador do significado do trabalho na relação entre a liderança ética e a satisfação dos colaboradores. VI Conferência em Investigação e Intervenção em RH. 18 e 19 de fevereiro de 2016. Escola Superior de Ciências Empresariais (ESCE) do Instituto Politécnico de Setúbal (IPS). http://www.eseig.ipp.pt/conferencias/index.php/iirh/viconferencia-ii (Abstract)

sociedade reagem mais fortemente às perceções de liderança ética através de maior satisfação no trabalho.

Limitações. Atendendo que todas as variáveis foram obtidas no mesmo instrumento de medida e em simultâneo, os dados podem padecer de problemas relacionados com a variância do método comum. Trabalhos futuros devem investigar a existência de variáveis mediadoras na relação entre as perceções de liderança e os níveis de satisfação. 